\title{
Conception and Realization of a PV System Provided with a Sun Tracker Operating at Dual Axis
}

\author{
R. GAAMOUCHE, A. LAMKADDEM, S. TALBI, K. KASSMI \\ * Mohamed Premier University, Faculty of Science, dept. of Physics, Laboratory LETSER (Team MEER), Oujda, Morocco. \\ E-mail: khkassmi@yahoo.fr
}

\begin{abstract}
In this paper, The researchers present the conception, the realization and the experimentation of a photovoltaic (PV) system provided with a sun tracker reliable and low cost operating at dual axis. The tracker's role is to orient the PV generator, whose weight is about $9 \mathrm{Kg}$, perpendicular to the sun with very good accuracy. This tracking is based on the use of four LDR sensors, which detect the intensity of light scattered by a sun processing unit, from command and control (UTCC), which manages all of the sun tracking tasks (the end detection of parcours, regulation of the power supplied by the PV panels (Command MPPT), ... ). The results obtained show a significant improvement of the energy produced, compared to conventional PV installations where generators are fixed and oriented south at a tilt $45^{\circ}$. During a day of operation, improvement could reach $41 \%$ and consumption of the tracking does not exceed $0.55 \%$ of the energy production produced by the PV generator (an improvement of $5 \%$ compared to existing trackers).
\end{abstract}

Keywords - Orientation of the photovoltaic generators, maximum power, tracker of the sun, microcontroller, LDR sensors, optimal collection of illumination, end detection of purposes parcours, MPPT command, consumption of energy, cost.

\section{INTRODUCTION}

The renewable photovoltaic energy (PV) is in the center of all attentions mainly because of its safety character to the environment [1]. This represents, certainly, a release track overlooked from the consumption mode of fossils energies. However, the conversion system to PV energy presents problems related to the yields of PV generators which do not pickup sufficient intensity of the solar radiation [2]. This is due to the positioning of the PV generators and to the type of system that ensures sunlight racking. In general, there is a multitude of methods and techniques that can be divided into two main categories [3]:

- The automatic tracking systems which use optical sensors to detect the position of the sun and then, initiate if necessary, motion of the tracker of the PV generator [4]. Their major disadvantage is additional losses of energy due to the consumption of the control system which remains activated permanently [5].

- The automatisms to calculate forecasts of the sun path in order to start or not the tracking system, by comparison with the real trajectory. This is called then programmed trackers (regulated) or astronomical pursuit [6]. In this type of technique, the tracking depends on the zone in which the system will be located.

- Currently, the sun tracking systems proposed in the literature have the disadvantages [7]: complicated regulation [8], complex structure [9], mechanical stability problems, consumption when tracking the sun (greater than $8 \mathrm{Wh} /$ day, for a panel of 100 WCrete) and high cost [10].

In order to enhance reliability of the structure, the functioning, the consumption and the cost of the sun tracker, the researchers propose in this paper the conception of a sun tracker system operating at dual axis two axes having the technical characteristics:

- Moving a PV generator of 200 W Crete and a weight of the order of $5.4 \mathrm{~kg}$,

- the operative part is molting thanks to two motors,

collecting the irradiance intensity by using four sensors LDR [11],

- the command part uses a processing unit, command and control (UTCC), programmed for the piloting of the actuators in order to track with 
precision the trajectory of the sun depending on the illumination image voltages from LDR sensors, and voltage from the specific circuitry to automatically detect from purposes parcours (sunrise and sunset, ...).

The researchers first present the structure and the functioning of each bloc of PV system provided with the sun tracker. Then, they analyze the experimental results concerning the functioning of the complete system during a the whole day. An attention will be particularly given to production and losses of energy in each bloc of the system: PV generators, DC/DC converter, tracker, $\ldots$.

\section{CONCEPTION AND FUNCTIONING OF THE PV SYSTEM PROVIDED WITH A SUN TRACKER}

\section{A. Structure of the PV system}

The bloc diagram of the PV system provided with a sun tracker operating at dual axis is presented on figure 1. This system is conceived to track the maximum intensity of the diffuse light by the sun during the whole day. It has the following blocs:

- Four LDR sensors (C1, C2, C3 and C4) positioned in four locations of the PV panel. They provide voltages depending on the intensity of illumination [9]. The displacement of the PV panel depends strongly on these voltages.

- A PV generator [12] which provides a power of 180 $\mathrm{W}$, under a voltage of $35.8 \mathrm{~V}$ and a current of $5 \mathrm{~A}$.

- A DC/DC converter "Boost" [13] (figure 2). The components of the converter (Inductance L, capacities CE and CS) are dimensioned so that this one operates at a quench frequency of $10 \mathrm{kHz}$ and a power which could reach $500 \mathrm{~W}$.

- A digital MPPT command [13] which allows searching the maximum power point (MPP) of the PV panel $[14,15]$ independently of meteorological conditions (irradiance, temperature) and the load.

- A resistive load.

- A sun tracker composed by:

- a mechanical system that tracks the position of the sun automatically, by varying two angles of the support of the PV panels following a horizontal rotation (East and West) and a vertical rotation (North and South)[16]. This mechanical system is ordered by an electronic board based on a microcontroller through two actuators: the first one acts on the horizontal axis and the second on the vertical axis.

- The actuators used are two electric jacks based on engine with continuous current with a magnet permanent with a reducer (supporting voltages of $36 \mathrm{~V}$, current 4.8 A) [17]. The electric jacks used transform the rotational movement created by an electric motor in translator movement using a metal stem. The displacement of this stem varies linearly with the rotation speed of the engine and the system of transformation of movement. The choice of this type of jacks is justified by its availability on the market, its moderate cost, and its ease of use, besides it does not require other articulations during usage.

- a processing unit, command and control (UTCC) which represents the heart of the movements management of the PV generators used and the regulation of the power supplied by these (MPPT command). This bloc ( UTCC) is based on the use of a microcontroller provided with an oscillator with quartz of frequency $20 \mathrm{MHz}$ and a circuit of power which plays the role of an interface to realize all the spots: speed of both engines, direction of displacement and end detection of parcours (the West and the East).

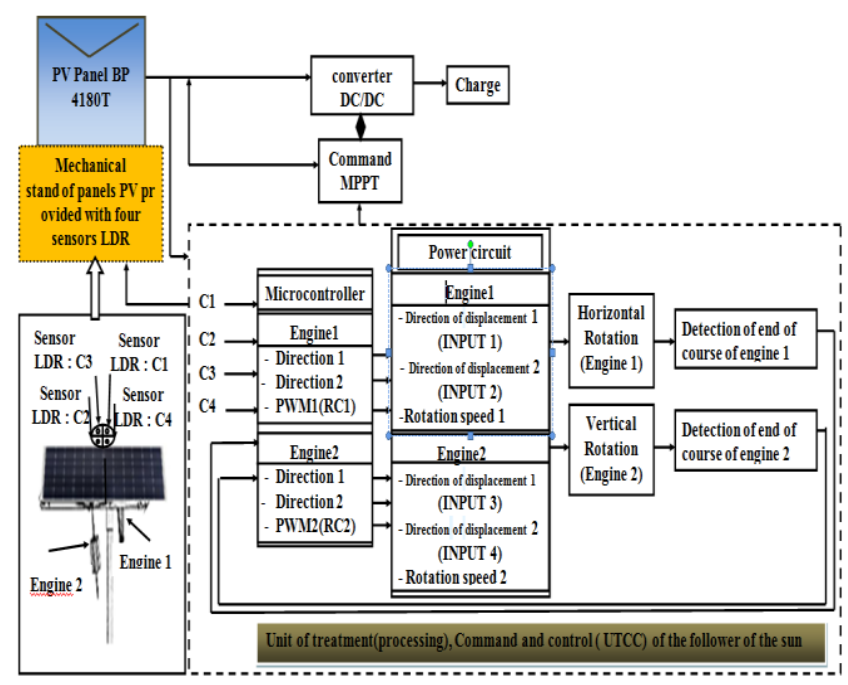

Fig .1. Schematic diagram of the solar system with the sun tracking. 


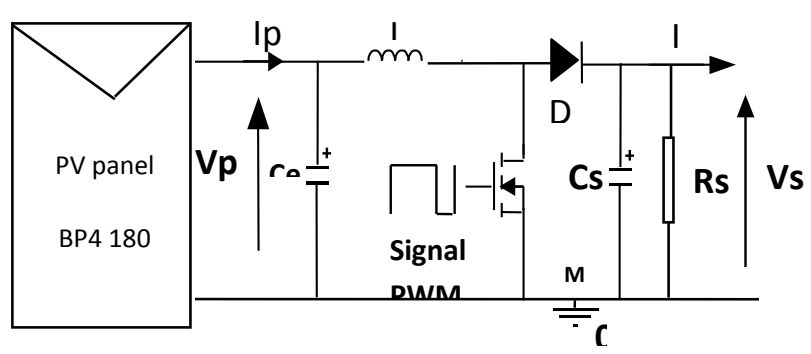

Fig .2. Structure of DC-DC converter "Boost".

\section{B. Functioning of the sun tracking system}

The functioning of the tracker at dual axis (Figure1), conceived and realized during this work, is based on the acquisition and the analysis of the voltages of the LDR sensors. This voltage decreases with the increase of the irradiance intensity received by the LDR sensors. The orientation of panels is made according to the information received and sent by the microcontroller of the UTCC unity in the following way:

- The microcontroller receives and exploits the imbalance created between four LDR sensors through the analog pines of the microcontroller.

- The microcontroller receives voltages from the specific circuits, realized during this work, to detect purposes of the parcours through the analog pines of the microcontroller.

- The rotation speed of engines is fixed by a signal PWM, sent by the microcontroller, of frequency $1500 \mathrm{~Hz}$ and of duty cycle 0,75 .

- The direction of displacement of motor movement is set by the power circuit [18] (H-bridge) based on the states of these inputs (INPUT 1, INPUT 2, INPUT 3 and INPUT 4). In table 1, the researchers have summarized the various situations which can take place (sens1, sens2 and stop).

The whole of tracking the sun tasks is realized by the microcontroller according to the algorithm of continuation represented in figure 3 :

- Configuration of input and output pines of the PIC,

- $\quad$ Reading of the various voltages (V1, V2, V3 and V4)

- which are proportional to illuminations of four LDR sensors ,

- Comparison of the voltages V1, V2, V3 and V4, converted by the PIC.

- Activation of the two pines RC1 and RC2 of the PIC to generate two PWM signals of frequencies 1500 $\mathrm{Hz}$ and of cyclical reports adequate to secure the speed of rotation of the two motors.

- Generation of the pulses (5 V or $0 \mathrm{~V}$ ) on the pines of the power module (Input 1 to 4 ) when the PIC detects an imbalance in the sensors voltage.

- Fixing the direction of the currents in the engines, following table 2, so that the PV panel picks up the maximum of the illumination power.

- Displacements of the engines with the possibility of detection of the ends of course.

Table 1. DIFFERENTES SEQUENCES DU SENS DE DEPLACEMENT DES MOTEURS 1 ET 2.

\begin{tabular}{|c|c|c|c|c|c|}
\hline $\begin{array}{c}\text { Input } \\
1\end{array}$ & $\begin{array}{c}\text { Input } \\
2\end{array}$ & $\begin{array}{c}\text { State motor } \\
1\end{array}$ & $\begin{array}{c}\text { Input } \\
3\end{array}$ & $\begin{array}{c}\text { Input } \\
4\end{array}$ & $\begin{array}{l}\text { State motor } \\
\quad 2\end{array}$ \\
\hline 0 & 0 & Stop Motor & 0 & 0 & Stop Motor \\
\hline 0 & 1 & $\begin{array}{l}\text { Direction } 1 \text { (EAST } \\
\text { towards the WEST) }\end{array}$ & 0 & 1 & $\begin{array}{l}\text { direction } 1 \text { (SOUTH } \\
\text { towards the NORTH) }\end{array}$ \\
\hline 1 & 0 & $\begin{array}{l}\text { Direction } 2 \text { (WEST } \\
\text { towards the EAST) }\end{array}$ & 1 & 0 & $\begin{array}{l}\text { Direction } 2 \text { (NORTH } \\
\text { towards the SOUTH) }\end{array}$ \\
\hline 1 & 1 & Stop Motor & 1 & 1 & Stop Motor \\
\hline
\end{tabular}




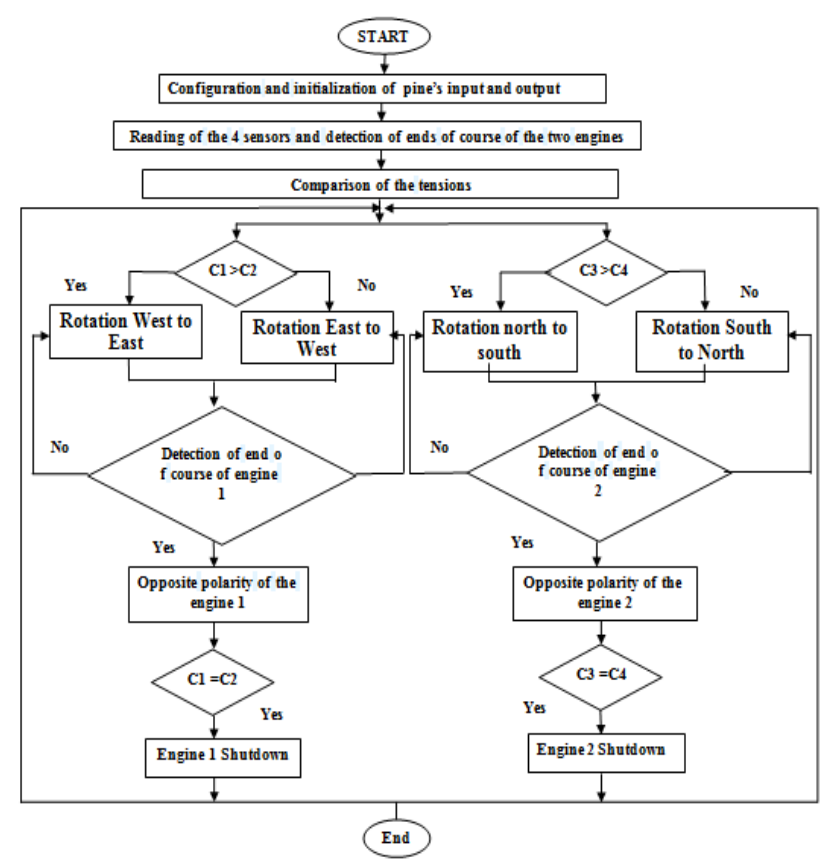

Fig .3. Algorithm of a tracker of the sun in two axes.

\section{EXPERIMENTAL RESULTS}

\section{A. Experimental procedure}

Figure 4 represents the bench electrical measurement automated and the PV system, fitted with the tracker, conceived and made in the researchers' laboratory during this study. The bench and the system are composed by:

- Equipment of measures connected to computer: multimeter (Keithley 2700), digital oscilloscope...

- PV Panel (180 Wcrete) in monocrystalline silicon is provided by a pyranometer with Meteon which measures the value of illumination directly.

- Tracker of the sun whose role is to position the panel perpendicular to the sun in order to collect the maximum of the sun. It is formed by a mechanical support provided with two engines, in order to direct panel PV along two axes, and of a control unit (UTCC).

- $\quad$ An energy DC-DC converter type 'Boost' fitted with a MPPT command which follows the maximum power point (PPM) of the PV panel.

- A resistive charge of value $50 \Omega$

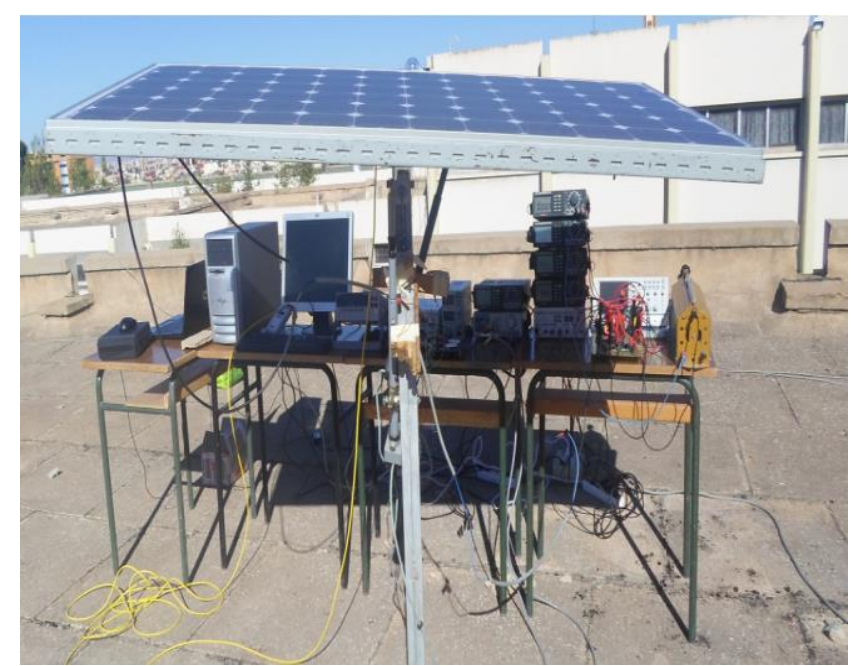

Fig .4. Bench of automated measurements, prototype photovoltaic (panels, tracker of the sun, Converter Boost MPPT command).
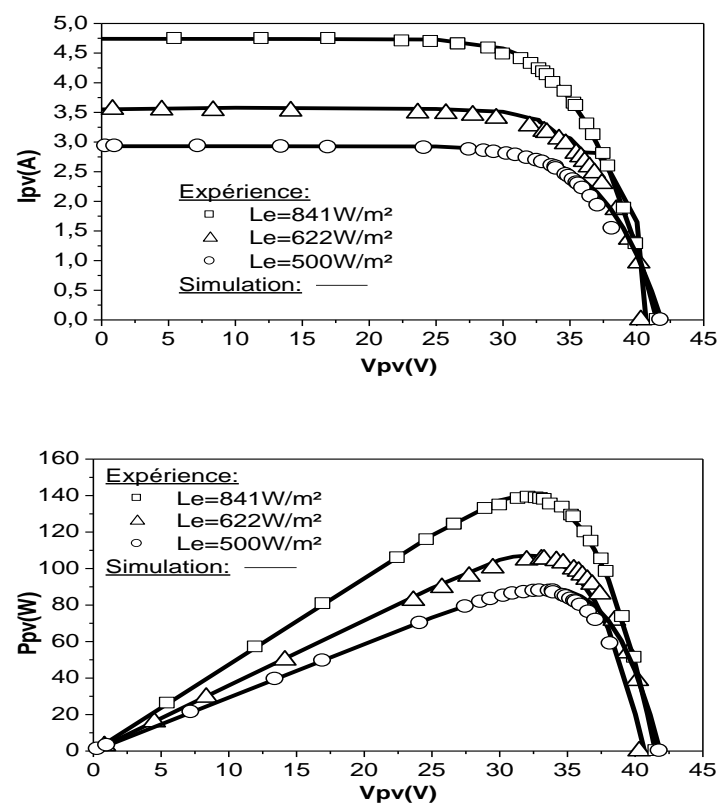

Fig .5 Experimental and simulated Current-Voltage and PowerVoltage characteristics

\section{B. Electrical characteristics of photovoltaic panels}

The researchers have characterized the PV panel used for a whole day where the intensity of irradiance varies between $400 \mathrm{~W} / \mathrm{m}$ to $900 \mathrm{~W} / \mathrm{m}^{2}$ and the temperature 26 ${ }^{\circ} \mathrm{C}-30^{\circ} \mathrm{C}$. In Figure 5, the researchers present the typical characteristics of the current-voltage and the power voltage obtained. On the same figures, they present the simulated characteristics in Pspice by setting the parameters of the diode (saturation current, ideality factor, ...), which allow them to obtain the experimental results. The results show good agreement between experiment and simulation throughout the range of the intensity of the illumination. 
In the validation part of the operation of the tracker, the researchers use the parameters fixed in the simulations.

\section{Functioning of the $L D R$ sensors}

Furthermore, the researchers have tested the operation of the LDR sensors during a day when the intensity of irradiance reached $1000 \mathrm{~W} / \mathrm{m} 2$. In figure 6 , the researchers represent the typical evolution of the voltage at the terminals of the sensors with the intensity of the illumination. In the same figure 5 , they have deferred the results of simulation got in ISIS Proteus [19]. These results show on the one hand a very good agreement between the experiment and the simulation, and on the other, that when illumination varies from $200 \mathrm{~W} / \mathrm{m} 2$ to $1000 \mathrm{~W} / \mathrm{m} 2$, the voltage at the terminals of the LDR varies from $300 \mathrm{mV}$ to $60 \mathrm{mV}$ (decrease of the voltage of $20 \%$ when the illumination increases of $200 \mathrm{~W} / \mathrm{m} 2$ ).
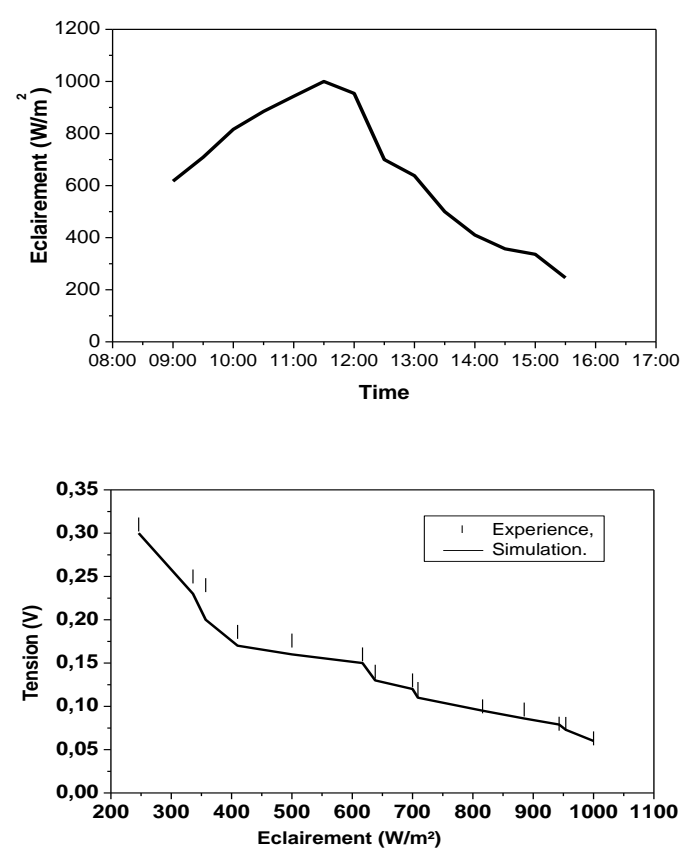

Fig .6 Variation of the irradiance and the voltage in function of the illumination during a day.

\section{Functioning of the tracker}

The typical function of the tracker bloc is presented in figures 7 to 11, when the maximum intensity of illumination on sensors $\mathrm{C} 1$ and $\mathrm{C} 2$ is detected. The same function is obtained on the $\mathrm{C} 3$ and $\mathrm{C} 4$ sensors. The results show:
- The PIC detects the imbalance between sensors $\mathrm{C} 1$ and $\mathrm{C} 2$ (Figure 7) and generates PWM signals of amplitude $4 \mathrm{~V}$, frequency $1500 \mathrm{~Hz}$ and duty cycle $\alpha=0.75$ (Figure 8). Under these signals, engine 1 rotates with a very satisfactory speed and a $0.19 \mathrm{~A}$ current (Figure 9) to achieve the equilibrium position of the LDR sensor and hence the maximum illumination intensity.

- C1 sensor senses high intensity light from sensor $2(\mathrm{~V} 1<\mathrm{V} 2)$ (Figure 7), the control system of the tracker supplies motor 1 with activating Input $1=1$, Input2 $=0$ of the power circuit (Figure 10). The PV panel moves from west to east under motor $10.19 \mathrm{~A}$ current (Figure 9). Since the panel is close to the optimal position, the light intensities received by the LDR C1 and C2 increase and the two voltages V1 and V2 decrease (Figure 7). When these two LDR sensors receive almost the same intensities (V2»V1) (Figure 7), the tracker control system detects the optimal position of the lighting, following the direction WEST / EAST and generates a zero current (Input $1=\operatorname{Input} 2=0$ ) to stop the engine displacement 1 (Figures 9 and 11).

All the results obtained in this paragraph show the good functioning of the circuits and blocs of the tracker, conceived and realized in this work: good detection of the light intensity and displacement the PV panel to the optimal position illumination.

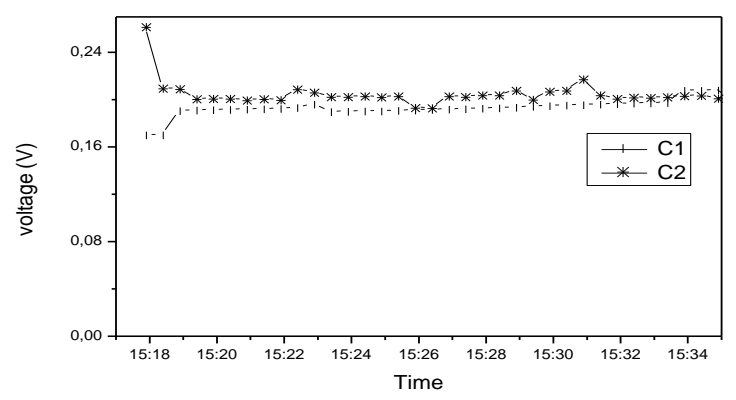

Fig .7 Variation of the voltage LDR C1 and C2 sensors. 


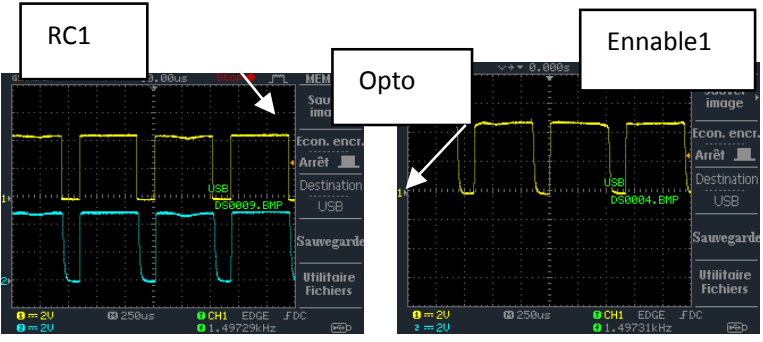

Fig .8 PWM1 signal at the outputs of the PIC (Pin: RC1) of the Optocoupleur, and at the input (Ennable1) of the power circuit (scales: 2 V / Div, 25 microseconds / Div).

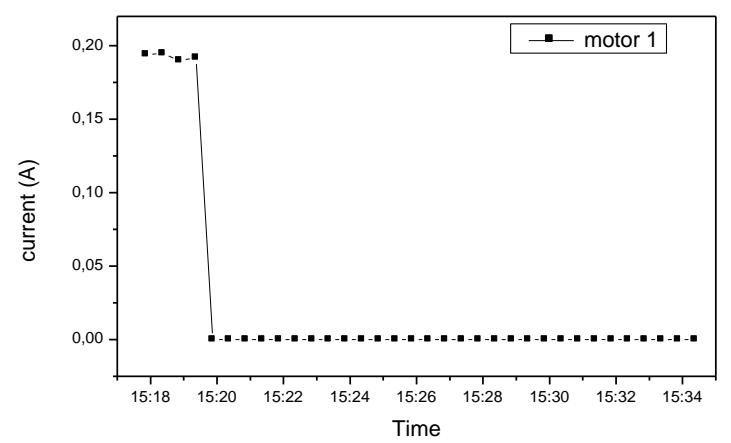

Fig .9 Supply current of motor 1 during the equilibrium of the LDR $\mathrm{C} 1$ and $\mathrm{C} 2$ sensors.

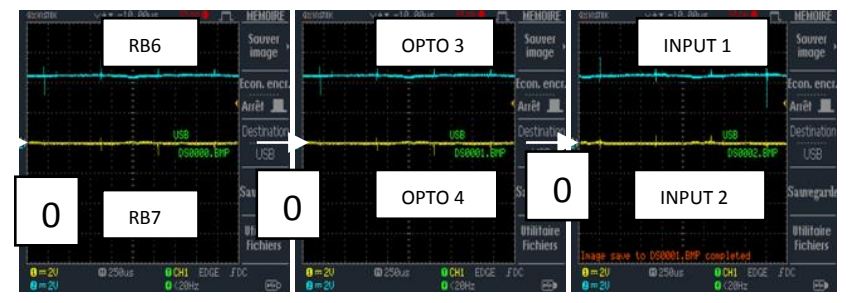

Fig .10 States of the Pins RB6 et RB7 of PIC , the outputs of the Optocoupleurs and the input of the power circuit upon the rotation of the during the rotation of the motor the WEST to the EAST (scale: $2 \mathrm{~V} /$ Div, 25 microseconds / Div).

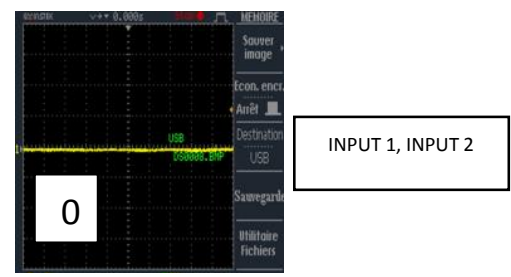

Fig.11. States of INPUT 1 and 2 of the power circuit during detection of the equilibrium LDR C1 and C2 sensors following a displacement of the WEST to the EAST (scale: 2 V / Div, 25 microseconds / Div ).

\section{E. Functioning of the $D C / D C$ converter}

In Figure 11, the researchers present the typical wave forms of the PWM signals generated by the MPPT control, the terminals of the inductor, the diode and the output of the power switch. These results show:

- The MPPT command generates a signal of frequency $10 \mathrm{kHz}$ and a duty cycle of 0.63 . The comparison of this value and the optimal [12] shows that the converter is controlled under the optimum conditions and the PV panel runs around the PPM [13-20].

- When the switch is closed:

The output voltage of each switch is $:(\mathrm{Vds}=0 \mathrm{~V})$,

The voltage across the inductance is:

$$
\mathrm{VL} 1=\mathrm{Vpv} 1=36.3 \mathrm{~V}
$$

The diode is blocked and its voltage is equal to:

$$
V s=-74 V(\text { fig. 12.D) }
$$

When the switch is opened:

The output voltage of the switch is equal to the output because the diode conducts (fig 12.B) :

$$
\mathrm{Vds}=\mathrm{Vs}=74 \mathrm{~V},
$$

The potential difference to the terminal of the inductor is (fig 12.C) :

$$
\mathrm{VL}=\mathrm{Vpv}-\mathrm{Vs}=-37.7 \mathrm{~V}
$$

All the results obtained in this section show the good functioning of each active component and liabilities of the $D C / D C$ converter in optimal conditions. 

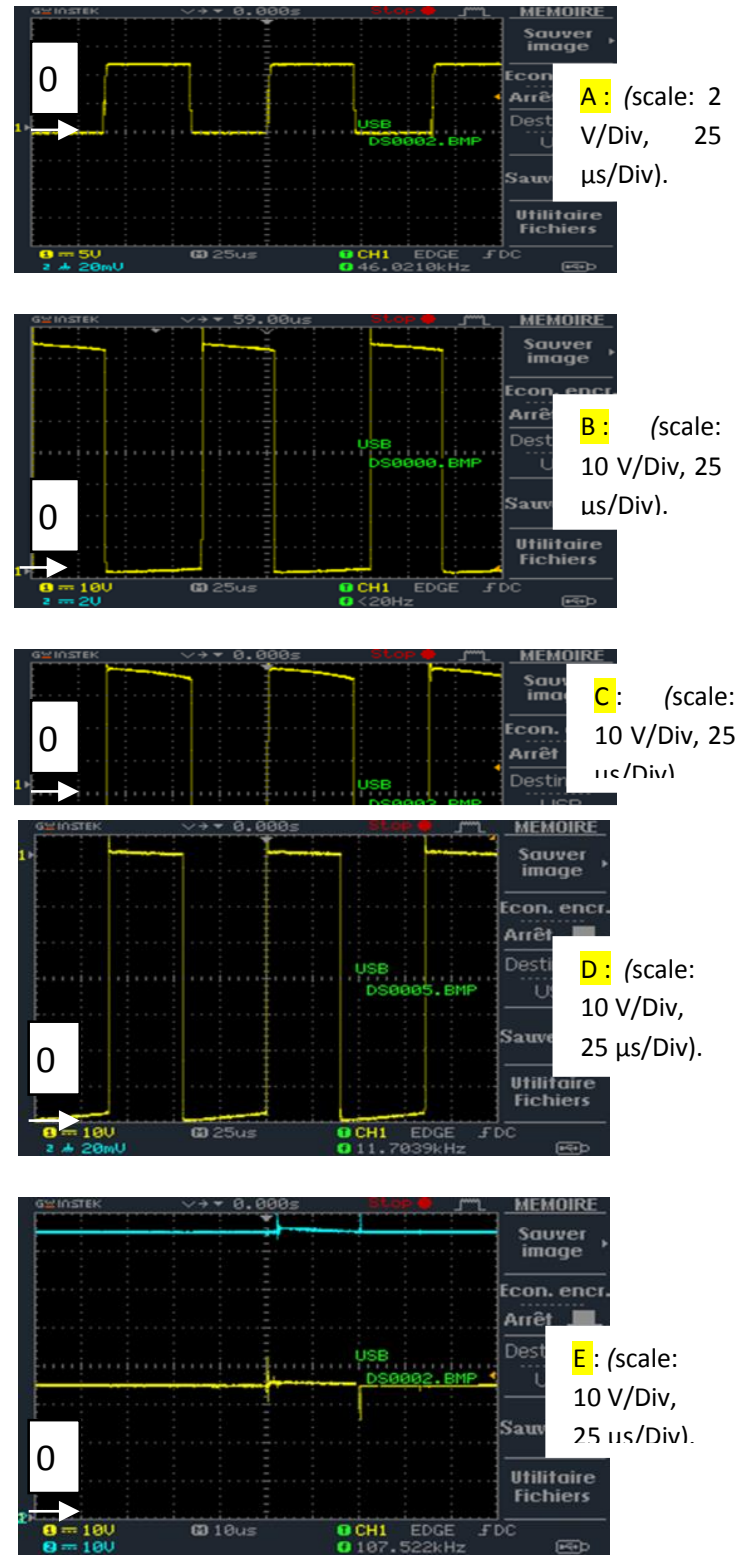

Fig.12. - Wave form:

A : PWM generated by the MPPT control.

$B$ : The output voltage of the power switch

$C$ : Voltage across the inductor.

$\mathrm{D}$ : Voltage across the diode.

DC-DC.

$\mathrm{E}:$ Voltage at the input (Vpv) and to the output of the

\section{F. Functioning of the $D C / D C$ converter}

The researchers have analyzed the functioning of the PV system provided with the sun tracker (Figure 4) during a whole day of operation. In order to validate the obtained results, they have carried out a comparative study compared to the classic installation by experimenting the same PV system when the panel PV is fixed and oriented southward of an inclination of 45 $\circ$.

In Figure 13, they show the results obtained: irradiance, duty cycle of the command MPPT, the electric greatnesses (voltage, current and power) at the input and output of the DC/DC converter and the efficiencies of the DC/DC converter and the complete system. In the same figures 13.B to $D$, they represent the optimal simulation results. From the obtained results, they have deducted the energy produced by the panel PV, in the case of both installations (system PV with and without tracker) so there is a loss of energy in the case of the classic installation. All results show:

- A very good agreement between experiment and the simulation.

- The electric greatnesses are improved remarkably with the tracker. The energy produced by the PV panel on the order of $820.47 \mathrm{Wh}(628.46 \mathrm{Wh})$ in the presence (absence) of the tracker (an improvement of $23.4 \%$ ). Power losses are very important and can reach $8 \%$ (with tracker) $\quad(41 \%$ without tracker) at noon (beginning and end of the day).

- The efficiencies of the converter (superior to $90 \%$ ) and the global system (of the order of $13.87 \%$ ) are very satisfactory. They are considered among the best in the literature.

- The energy consumed by the tracking system of the sun for a whole day of operation does not exceed $4.55 \mathrm{Wh}$, This value is significantly better compared to that of the literature which is 6 to $9 \mathrm{Wh}$ [21].

All the obtained results show the good functioning and very interesting performances of the PV system provided with the tracker conceived and realized during this work. 

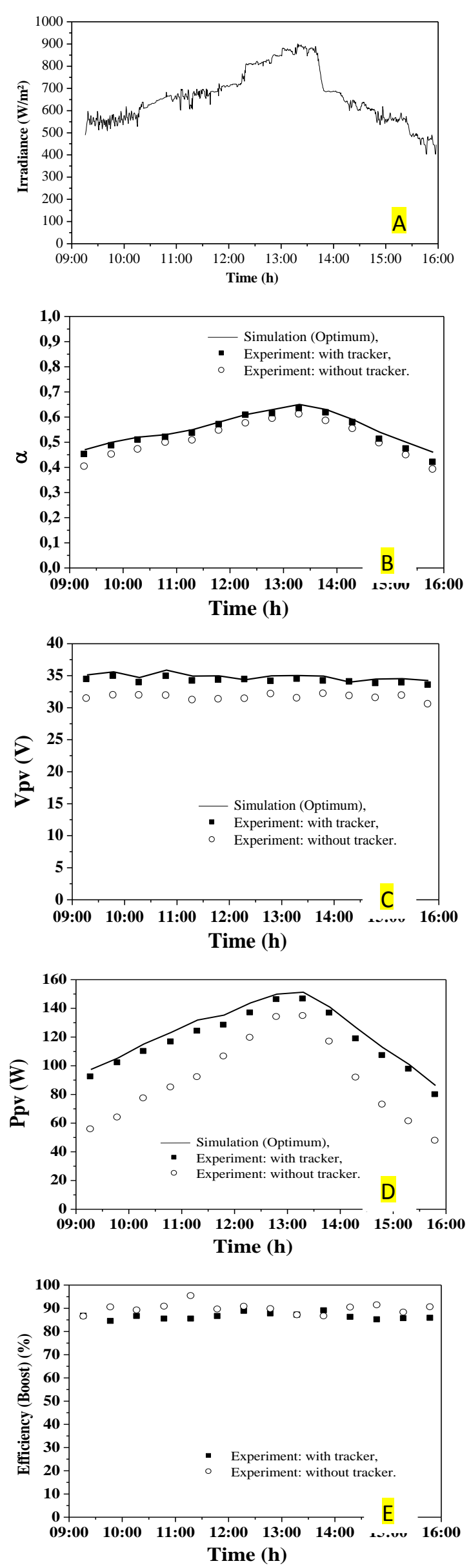
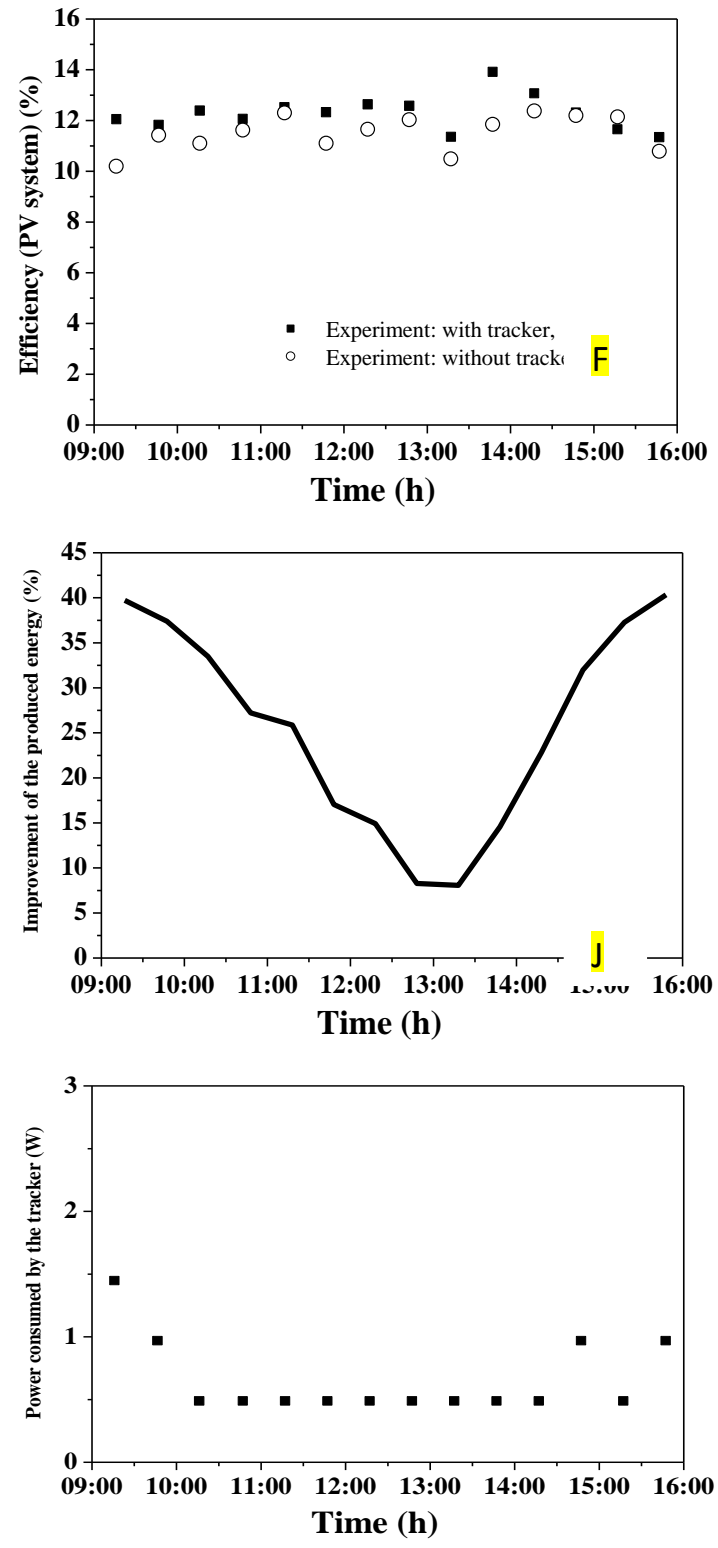

Fig.13. Electrical quantities, experimental and simulated (Optimal) a PV system with a follower system of the sun and a PV system facing south with a $45^{\circ}$ inc

- Variation of the irradiance (A),Variation $0^{\circ} \mathrm{H}$ uty cycle (B)., - the voltage Vpv (C), the power Ppv (D) .

- Power losses to the level of the DC-DC converter (E). - The efficiency of the global system $(F)$.

- The losses of a PV system with a tracking system of the sun relative to a fixed system (J).

- Consumption of a tracker system of the sun $(\mathrm{H})$.

\section{CONCLUSION}

The PV system provided with a sun tracker operating at dual axis, conceived and realized in this work, shows on the one hand the good functioning of the tracker and on the other, the very satisfactory performances. By comparing 
with the PV systems provided with the classic trackers or fixed PV generators, the researchers have shown improvements of the produced energy which could reach $41 \%$, weak consumption of the tracker $(<0.55 \%$ of the product energy, either improvement of $5 \%$ with respect to currents trackers) and very interesting costs.

In perspective, the tracker conceived in this work will be used in PV installations (2-3 kW) realized in the isolated site of Douar Zragta, Rural District of Oujda-Angad Prefecture (Pumping and lighting). These installations are carried out by the concerned research team with support from United Nations Projects Art Gold Morocco and Belgian Development Agency in Morocco CTB (Project MIP 10/12).

\section{ACKNOWLEDGEMENTS}

This work is realized in the frame:

- Belgian Development Agency BTC (Project MIP/012/010).

- PNUD Art Gold Marocco Program, 20082 ENV OO.

- Cooperation Morocco-Belgian "Institutional University Commission" IUC-Oujda 20082012 (Water and Environment Activity/SubActivity Renewable Energy).

- Moroccan-Tunisian Cooperation SCIENTIFIC RESEARCHAND TECHNOLOGY project (11/MT/38).

\section{REFERENCES}

[1] B. Pandey1, A. Agrawal2"Automatic sun tracking system using PSoC", International Journal of Innovative Research in Science, Engineering and Technology, Vol. 1, Issue 1, November 2012.

[2] A. Ponniran, A. Hashim, A. Joret "A design of low power single axis solar tracking system regardless of motor speed ", International Journal of Integrated Engineering, Vol. 3 No. 3 (2011) .

[3] B. S. K. Ray, M. Abul Bashar, A.Maruf,F. Bin Sayed "Two
[4] ways of rotating freedom solar tracker by using ADC of microcontroller " Global Journal of Researches in Engineering, Vol. 12 Issue 4 Version 1.0, 2012,ISSN: 0975-5861

[5] J. Axaopoulos, P. Emmanouil .M. Fylladitakis, "Energy and economic comparative study of a tracking vs a fixed photovoltaic system", European Scientific Journal April 2013 edition vol.9, No.12 ISSN: 1857 - 7881 (Print) e - ISSN, pp. 1857- 7431.

[6] H. Mousazadeh, A. Keyhani , A. Javadi , H. Mobli ,K. Abrinia , A. Sharifi, "A review of principle and sun-tracking methods for maximizing solar systems output," Renewable and Sustainable Energy Reviews, vol. 13, January 2009, pp. 1800-1818.

[7] L .Alboteanu, G. Manolea, F. Ravigan, "Positioning systems for solar panels placed in isolated areas," Annals of the University of Craiova, Electrical Engineering.

[8] O. Bingol, A. Altintas, Y. Öner, "Microcontroller based solar-tracking system and its implementation," Journal of Engineering Sciences , 12, 2, 2006, pp. 243-248

[9] M. Rebhi, M. Sellam, A. Belghachi, B. Kadri, “ Conception and realization of sun tracking system in the south-west of Algeria, " Applied Physics Research ISSN: 1916-9639 Vol. 2, No. 1, May 2010. pp. 66-75

[10] S. Zubair, A. Suleiman, H. T. Abdulazzez, B. A. Salihu, "Design and construction of a microcontroller based single axis solar tracker, " al / Innovations in Science and Engineering 1 (2011).

[11] http://www.solarkit.com/epages/62035995.sf/fr_ BE/?ObjectPath=/Shops/62035995/Categories/traceur-solaire-suntracer-

[12] Bhavesh Pandey, Anita Agrawal, "Automatic sun tracking system using PSoC, " International Journal of Innovative Research in Science, Engineering and Technology, Vol. 1, Issue 1, , pp. November 2012, pp. 66-70. 
[13] Kais I. Abdul-lateef, "A low cost sin gle-axis sun tracker system using pic microcontroller," Diyala Journal of Engineering Sciences Vol. 05, No. 01, June 2012, pp.65-78,.

[14] http://greenforcesolar.com.au/wordpress/wpcont ent/uploads/2011/04/BP_4180T_solar_panel.pdf

[15] M. El Ouariachi, T. Mrabti, Ka. Kassmi and K. Kassmi, "Regulation of the electric power provided by the panels of the photovoltaic System," International Journal of Physical Sciences, Vol. 4, No5, May 2009, pp. 294 -309,.

[16] M. Melhaoui, E. Baghaz, K. Hirech, M. F. Yaden and K. Kassmi, "Contribution to the improvement of the MPPT control functioning of Photovoltaic systems," International Review of Electrical Engineering (I.R.E.E.), v. 9, n. 2, pp. 393-400, apr. 2014. ISSN 1827-6679.

[17] F.Pinhelli,G. C. Neto, S. L.Stevan, " Automation For solar tracker for panel photovoltaique efficiency analysis", Iberoamerican Journal of Applied Computing, Vol. 2, No. 2, Aug.2012, ISSN pp. 2237-4523

[18] S. Zubair, A. Suleiman, H. T. Abdulazzez, B. A.
Salihu, "Design and construction of a microcontroller based single axis solar tracker," al / Innovations in Science and Engineering 1 (2011).

[19] M. F. Yaden, M. Melhaoui, R. Gaamouche, K. Hirech, E. Baghaz, K. Kassmi, "Photovoltaic system equipped with digital command control and acquisition," Electronics.; 2(3) 2013, pp. 192-211.

[20] P. S. Pandiarajan, C. Mukuntharaj, "Effective power generation system for day and night using solar power with tracking a molten salt techniques," International Journal of Engineering Research \&Technology (IJERT), Vol. 1 Issue 6, August -2012, ISSN: pp. 2278-0181 .

[21] N. W. Gosim, T. Faisal, H. Al-Assadi, and M. Iwan, "Pick and place ABB working with a liner follower robot," Procedia Engineering 41 2012), p. 1336.

[22] http://www.labcenter.com/index.cfm

[23] A. Salsabila ,S. Suhaidi ,Z.A.A.K Mohd, "Power feasibility of a low power consumption solar tracker," Procedia Environmental Sciences, 17 ( 2013 ),pp. $494-502$. 